\title{
Qualidade de mudas de berinjela submetida a diferentes métodos de produção ${ }^{1}$
}

\author{
The quality of eggplant seedlings under different production methods
}

\author{
Edilson Costa ${ }^{2 *}$, Lucas Gustavo Yock Durante ${ }^{3}$, Pedro Luiz Nagel ${ }^{3}$, Cleber Rezende Ferreira ${ }^{3}$ e Adriano dos \\ Santos $^{3}$
}

Resumo - Produzir mudas de berinjela com boa qualidade é essencial para obter um sistema de cultivo uniforme e produtivo. Estas podem ser formadas em substratos orgânicos e minerais, ou misturas destes. Desta forma o presente trabalho avaliou a vermiculita e manivas de mandioca triturada, puras e em misturas, na formação de mudas de berinjela, em dois tipos de ambientes e dois recipientes. Utilizou-se o viveiro agrícola telado em monofilamento, malha com $50 \%$ de sombreamento e a estufa agrícola em arco, coberta com filme polietileno, com fechamentos de tela de monofilamento, malha para $50 \%$ de sombreamento. Em cada ambiente foram testadas as bandejas de poliestireno de 72 e 128 , preenchidas com " $0 \%$ vermiculita e $100 \%$ ramas", " $20 \%$ vermiculita e $80 \%$ ramas", " $40 \%$ vermiculita e $60 \%$ ramas", " $60 \%$ vermiculita e $40 \%$ ramas", " $80 \%$ vermiculita e $20 \%$ ramas" e " $100 \%$ de vermiculita e $0 \%$ ramas". O delineamento experimental foi o inteiramente casualizado no esquema fatorial de parcelas sub-subdivididas ( 2 ambientes $\times 2$ recipientes x 6 substratos), totalizando 24 tratamentos. A tela de monofilamento é o melhor ambiente de cultivo quando se utiliza a bandeja de 72 células, e para a bandeja de 128 células a estufa agrícola propicia melhores condições. O melhor recipiente para formação de mudas de berinjela é a bandeja de 72 células. As composições medianas de vermiculita e ramas de mandioca, entre 40 e $60 \%$, formam o melhor substrato para as mudas de berinjela. O índice de qualidade de Dickson é um bom indicador do padrão de qualidade de mudas de berinjela.

Palavras-chave - Berinjela. Vermiculita. Mandioca.

\begin{abstract}
Producing good-quality eggplant seedlings is essential for a uniform system of cultivation and yield. The seedlings can be grown in organic or mineral substrates, or a mixture of these. This study evaluated the effect of vermiculite and crushed cassava stems, both pure and as a mixture, on eggplant-seedling growth in two types of environment and in two different types of container. A nursery greenhouse and poly-tunnel greenhouses, both with monofilament screening and $50 \%$ shading, were used. In each environment polystyrene trays of 72 and 128 cells were tested. These were filled with: $0 \%$ vermiculite and $100 \%$ cassava stems; $20 \%$ vermiculite and $80 \%$ cassava stems; $40 \%$ vermiculite and $60 \%$ cassava stems; $60 \%$ vermiculite and $40 \%$ cassava stems; $80 \%$ vermiculite and $20 \%$ cassava stems, and $100 \%$ vermiculite and $0 \%$ cassava stems. The experimental design was completely randomized into a scheme of subdivided sub-plots (2 environments x 2 containers $\times 6$ substrates) totaling 24 treatments. The monofilament screen is the best environment when using a tray of 72 cells. For trays of 128 cells, the greenhouse provides the best conditions. The best container for eggplant seedlings is the tray of 72 cells. The median mixtures of vermiculite and cassava stems, between 40 and $60 \%$, are the best substrate for the eggplant seedling. The Dickson quality index is a good indicator of the standard of quality of the eggplant seedlings.
\end{abstract}

Keywords - Solanum melongena. Vermiculite. Cassava stems.

\footnotetext{
* Autor para correspondência

${ }^{1}$ Recebido para publicação em 10/09/2010; aprovado em 03/06/2011

Projeto de pesquisa financiado pela Pró-Reitoria de Pesquisa e pela Gerência da Unidade de Aquidauana

${ }^{2}$ Universidade Estadual de Mato Grosso do Sul-UEMS/Aquidauana, Rodovia Aquidauana - Uems, Km 12, zona rural, Caixa Postal 25, Aquidauana-MS, Brasil, 79.200-000, mestrine@uems.br

33raduandos do Curso de Agronomia/UEMS, Aquidauana-MS, Brasil, franklucasnaz@yahoo.com.br, nagelpedro@yahoo.com.br, bimcleber@ yahoo.com.br, adriano.agro84@yahoo.com.br
} 


\section{Introdução}

Na cadeia produtiva de hortaliças de boa qualidade, a formação de mudas é uma das fases mais importantes para o ciclo da cultura, influenciando diretamente no desempenho final da planta, tanto do ponto de vista nutricional como do produtivo, pois existe uma relação direta entre mudas sadias e produção a campo (CAMPANHARO et al., 2006). Mudas bem formadas podem incrementar a produção, enquanto que mudas mal formadas, segundo Guimarães et al. (2002) podem ampliar o ciclo da cultura e, conseqüentemente, causar prejuízos ao produtor.

A produção de mudas em sementeira ocasiona lesões no sistema radicular durante o transplante e permite a entrada de patógenos, comprometendo o desenvolvimento da planta. Com a modernização da horticultura e a formação de mudas em bandejas em cultivo protegido, utilizando substratos, obteve melhor qualidade e padronização das plântulas a serem levadas a campo e, conseqüentemente, maiores uniformização nos canteiros e maiores produtividades. Os diferentes volumes celulares das bandejas proporcionam padrões de qualidade distinta das plântulas conforme observado por Marques et al. (2003) e Trani et al. (2004) em mudas de alface, onde obtiveram melhores mudas em bandejas com maiores volumes celulares.

Com o cultivo protegido passou-se a produzir mudas com melhor qualidade fitossanitária, precoces e em diferentes épocas do ano (BEZERRA, 2003). Aliada à proteção das plantas, requisito como substrato passou a ser elemento importante na formação da futura planta, devendo possuir características desejáveis como baixo custo, fácil aquisição de nutrientes, capacidade de troca catiônica, esterilidade biológica, porosidade, retenção de umidade e uniformidade (SCHMITZ et al, 2002).

A berinjela (Solanum melongena L.) pertence à família das solanáceas, que compreendem o tomate, batata, pimentão, pimenta e jiló. Originária das regiões tropicais do Oriente, sendo cultivadas pelos chineses e árabes há séculos (FILGUEIRA, 2003). Devido à riqueza nutricional e propriedades medicinais está cada vez mais presente na mesa dos brasileiros (OLIVEIRA et al., 2009).

Esta hortaliça é uma espécie termófila que necessita de alta temperatura para seu desenvolvimento vegetativo e reprodutivo(SOUSA etal., 1997), proporcionando o cultivo na região do alto pantanal sul-mato-grossense. Em função dessa característica especial e considerando a necessidade de ampliar a oferta de hortaliças de qualidade no Estado de Mato Grosso do Sul, este trabalho teve como objetivo avaliar a formação de mudas de berinjela em substratos com porcentagens de manivas de mandioca triturada e vermiculita, utilizando bandejas com diferentes volumes celulares em dois ambientes de cultivo protegido.

\section{Material e métodos}

O experimento com berinjela, cultivar Embu, foi conduzido de março a julho de 2009 na área experimental da Universidade Estadual de Mato Grosso do Sul (UEMS), Unidade Universitária de Aquidauana, que se localiza na altitude de $174 \mathrm{~m}$, longitude de $-55,67^{\circ}$ e latitude de $-20,45^{\circ}$, região de interface entre Cerrado e Pantanal. O clima da região, de acordo com a classificação de Köppen é Aw, sendo definido como clima tropical úmido, com temperatura média anual de $29^{\circ} \mathrm{C}$.

Foram avaliados dois ambientes de cultivo: (A1) viveiro agrícola telado, de estrutura em aço galvanizado $(6,40 \times 18,00 \times 3,50 \mathrm{~m})$, fechamento em $45^{\circ}$, com tela de monofilamento, malha com $50 \%$ de sombreamento $\left(\right.$ Sombrite $\left.{ }^{\circledR}\right)$ e (A2) estufa agrícola em $\operatorname{arco}(6,40 \times 18,00$ $\mathrm{x} 4,00 \mathrm{~m}$ ) de estrutura em aço galvanizado, com abertura zenital na cumeeira, coberta com filme polietileno de $150 \mu \mathrm{m}$, difusor de luz, possuindo tela termorrefletora de $50 \%$ de sombreamento sob o filme e fechamentos laterais e frontais com tela de monofilamento, malha para $50 \%$ de sombreamento.

Em cada ambiente de cultivo as mudas foram testadas em 2 recipientes, sendo as bandejas de poliestireno de $72 \mathrm{e}$ 128, designados por R1 e R2, com as seguintes dimensões: 72 células $(5,0 \mathrm{~cm}$ de largura por $12,0 \mathrm{~cm}$ de altura e volume de $121,2 \mathrm{~cm}^{3}$ por célula) e 128 células $(3,5 \mathrm{~cm}$ de largura por $6,2 \mathrm{~cm}$ de altura e volume de $34,6 \mathrm{~cm}^{3}$ por célula). Estas foram preenchidas com substratos contendo mistura de vermiculita e manivas (ramas) de mandioca triturada nas seguintes proporções, em volume: (S1) " $0 \%$ vermiculita e $100 \%$ ramas"; (S2) "20\% vermiculita e $80 \%$ ramas"; (S3) " $40 \%$ vermiculita e $60 \%$ ramas"; (S4) "60\% vermiculita e $40 \%$ ramas"; (S5) " $80 \%$ vermiculita e $20 \%$ ramas" e (S6) " $100 \%$ de vermiculita e $0 \%$ ramas".

Para a avaliação dos experimentos se utilizou o delineamento inteiramente casualizado (DIC), em esquema de parcelas sub-subdivididas, com oito repetições, sendo a média de duas plântulas por repetição. As parcelas principais foram os ambientes de cultivo, as subparcelas as bandejas e as sub-subparcelas os substratos (dois ambientes $\mathrm{x}$ dois recipientes $\mathrm{x}$ seis substratos $=24$ tratamentos).

As manivas de mandioca foram trituradas em moinho de martelo (marca TRAPP, modelo TRF 650), utilizando a peneira de $8 \mathrm{~mm}$, posteriormente secadas a sol por uma semana, sendo revirada diariamente (TAB. 1 e 2). Foi utilizada vermiculita comercial de textura média.

Os substratos foram adubados com $2,5 \mathrm{~kg}$ de superfosfato simples $\left(18 \%\right.$ de $\left.\mathrm{P}_{2} \mathrm{O}_{5}\right), 0,3 \mathrm{~kg}$ de cloreto de potássio $\left(60 \%\right.$ de $\left.\mathrm{K}_{2} \mathrm{O}\right)$ e $1,5 \mathrm{~kg}$ de calcário dolomítico (100\% de PRNT), por metro cúbico de substrato (RIBEIRO et al., 1999). 
Tabela 1 - Resultado da análise das manivas de mandioca triturada. Aquidauana - MS, 2009

\begin{tabular}{|c|c|c|c|c|c|c|c|c|c|}
\hline $\mathrm{pH}$ & Umid. & C. Org. & $\mathrm{N}$ & $\mathrm{P}$ & $\mathrm{K}$ & $\mathrm{Ca}$ & $\mathrm{Mg}$ & $S$ & $\mathrm{Na}$ \\
\hline $\mathrm{CaCl}_{2}$ & -------- & -------- & --- & - & --- & ----- & ----- & $\mathrm{g} \mathrm{kg}$ & $\ldots$ \\
\hline 9,24 & 15,54 & 39,21 & 1,26 & 0,28 & 1,58 & 1,47 & 0,34 & 0,17 & 0,02 \\
\hline
\end{tabular}

Fonte: Análises realizadas no laboratório de solos da Embrapa Agropecuária Oeste $(\mathrm{CPAO}) ; \mathrm{pH}=$ potencial de hidrogênio iônico; Umid. = umidade do material; $\mathrm{C} . \mathrm{Org}$. = carbono orgânico; $\mathrm{N}=$ nitrogênio; $\mathrm{P}=$ fósforo; $\mathrm{K}=$ potássio; $\mathrm{Ca}=$ cálcio; $\mathrm{Mg}=$ magnésio; $\mathrm{S}=$ enxofre; $\mathrm{Na}=$ sódio

Tabela 2 - Porcentagem das partículas de manivas de mandioca trituradas, retida em cada peneira. Aquidauana - MS, 2009

\begin{tabular}{ccc}
\hline Peneira $\left(\mathrm{n}^{\circ}\right.$, ABNT $)$ & Furos $(\mathrm{mm})$ & \% do material \\
\hline 5 & 4,0 & 2,82 \\
10 & 2,0 & 50,85 \\
16 & 1,2 & 15,45 \\
30 & 0,6 & 19,87 \\
50 & 0,3 & 7,52 \\
100 & 0,15 & 2,47 \\
Fundo & 0,00 & 1,03 \\
\hline
\end{tabular}

Diâmetro geométrico médio $(\mathrm{DGM})=1,93 \mathrm{~mm}$; Módulo de Finura $(\mathrm{MF})=3,99$

A semeadura foi realizada em 02/06/2009, com três sementes por célula. $O$ início da emergência se deu no dia 13/06/2009, onze dias após a semeadura (11 DAS). O desbaste foi realizado em 28/06/2009. A irrigação foi manual com regador.

Foram mensuradas, com régua milimetrada, a altura de plântula (AP) nos dias 29/06 (27 DAS), 06/07 (34 DAS), 13 (41 DAS), 20 (48 DAS) e 27/07 (56 DAS). Para esta variável foi realizada análise de regressão em função do tempo utilizando o software Excel.
Aos 56 DAS foram mensurados, também, o diâmetro do colo (DC), massa seca da parte aérea (MSPA), massa seca do sistema radicular (MSSR) e massa seca total (MST). Foram determinadas as relações altura diâmetro do colo $^{-1}$ (RAD), massas secas aéreas.radiculares ${ }^{-1}$ (RMS) e índice de qualidade de Dickson (IQD = MST / $(\mathrm{RAD}+$ RMS) (DICKSON et al., 1960).

Foram coletadas as temperaturas de bulbo seco e bulbo úmido, nos horários de 09h:00 min, 12h:00 min e 15h:00 min de cada ambiente de produção, no período de 02 de junho a 27 de julho de 2009. Posteriormente, obteve a umidade relativa com o software Psychrometric Function Demo ${ }^{\circledR}$ (TAB. 3).

Os dados foram submetidos à análise de variância e as médias ao teste de Tukey, ao nível de 0,05 de probabilidade, utilizando o software Estat (1994).

\section{Resultados e discussão}

A relação entre a altura da plântula e o seu diâmetro do colo (RAD), nas bandejas, e o diâmetro do colo na interação entre ambiente e recipiente, não apresentaram diferenças significativas. Para as demais variáveis todos os tratamentos foram significativos. Esses resultados revelam que existe influência do tipo de ambiente, recipiente e substrato na formação da muda de berinjela, bem como esses fatores interagem

Tabela 3 - Temperatura $\left({ }^{\circ} \mathrm{C}\right)$ e umidade relativa (\%) nos horários das $09 \mathrm{~h} 00 \mathrm{~min}, 12 \mathrm{~h} 00 \mathrm{~min}$ e $15 \mathrm{~h} 00$ min para cada ambiente (A) de produção e externo. Aquidauana - MS, 2009

\begin{tabular}{|c|c|c|c|c|c|c|c|c|c|}
\hline & TBS & TBU & TBS & TBU & TBS & TBU & \multicolumn{3}{|c|}{----------------------UR----------------------- } \\
\hline & \multicolumn{2}{|c|}{ 09h00min } & \multicolumn{2}{|c|}{$12 \mathrm{~h} 00 \mathrm{~min}$} & \multicolumn{2}{|c|}{$15 \mathrm{~h} 00 \mathrm{~min}$} & $09 \mathrm{~h} 00 \mathrm{~min}$ & $12 \mathrm{~h} 00 \mathrm{~min}$ & $15 \mathrm{~h} 00 \mathrm{~min}$ \\
\hline A1 & 21,7 & 18,6 & 26,2 & 21,0 & 26,4 & 20,7 & 76,2 & 65,6 & 63,1 \\
\hline A2 & 21,8 & 18,3 & 26,4 & 20,3 & 26,8 & 20,7 & 72,9 & 60,2 & 60,6 \\
\hline EXT & 21,9 & 18,6 & 26,3 & 20,7 & 27,0 & 21,0 & 75,5 & 63,2 & 62,0 \\
\hline
\end{tabular}

TBS = temperatura de bulbo seco $\left({ }^{\circ} \mathrm{C}\right) ; \mathrm{TBU}=$ temperatura de bulbo úmido $\left({ }^{\circ} \mathrm{C}\right)$; UR = umidade relativa $(\%)$; A1 = viveiro telado com tela de monofilamento de 50\% de sombreamento; A2 = estufa agrícola; Ext = externo 
entre si para promover melhor desenvolvimento da plântula (TAB. 4).

Nas interações entre ambientes e recipientes, o maior volume celular da bandeja de 72 células, independente do ambiente de cultivo, sempre apresentou maiores valores nas variáveis analisadas, exceto na relação altura e diâmetro do colo na estufa agrícola, onde os recipientes não diferiram. Para a bandeja de 72 células o viveiro agrícola foi o ambiente mais adequado para o crescimento inicial da berinjela e para a bandeja de 128 células foi a estufa agrícola (TAB. 5).

O maior volume celular, por disponibilizar maior espaço para as raízes e maior quantidade de nutrientes, propiciou melhor desenvolvimento à muda de berinjela, concordando os resultados de Marques et al. (2003) e Trani et al. (2004) em mudas de alface, Echer et al. (2007) em mudas de beterraba, Modolo et al. (1999) em mudas de quiabeiro, Piovesan e Cardoso (2009) em mudas de abóbora e Seabra Júnior et al. (2004) em mudas de pepineiro.

Dependendo do tipo de recipiente, os ambientes de cultivo promoveram crescimento e desenvolvimento distinto das mudas de berinjela. Para a bandeja de 128 células, foram verificadas mudas menos vigorosas no viveiro telado, em que a própria estrutura da malha de sombreamento, a qual permitiu a entrada de água pluvial, pode ter carreado os nutrientes do menor volume de substratos e influenciado no desenvolvimento das plântulas. Fato não verificado para a bandeja de 72 células,

Tabela 4 - Valores de F calculado da análise de variância (ANOVA) aos 56 DAS. Aquidauana - MS, 2009

\begin{tabular}{crrrrrrrr}
\hline${ }^{\mathrm{C}} \mathrm{CV}$ & \multicolumn{1}{c}{$\mathrm{AP}$} & \multicolumn{1}{c}{$\mathrm{DC}$} & MSPA & \multicolumn{1}{c}{ MSSR } & \multicolumn{1}{c}{ RAD } & \multicolumn{1}{c}{ RMS } & \multicolumn{1}{c}{ MST } & \multicolumn{1}{c}{ IQD } \\
\hline $\mathrm{A}$ & $21,4^{* *}$ & $10,8^{* *}$ & $5,3^{*}$ & $8,4^{*}$ & $112,9^{* *}$ & $64,6^{* *}$ & $6,5^{*}$ & $4,7^{*}$ \\
$\mathrm{R}$ & $1976,4^{* *}$ & $650,2^{* *}$ & $3615,3^{* *}$ & $483,1^{* *}$ & $4,0^{\mathrm{NS}}$ & $213,6^{* *}$ & $4085,6^{* *}$ & $470,8^{* *}$ \\
$\mathrm{AR}$ & $48,8^{* *}$ & $3,7^{\mathrm{NS}}$ & $410,8^{* *}$ & $175,0^{* *}$ & $9,7^{* *}$ & $17,5^{* *}$ & $639,8^{* *}$ & $106,4^{* *}$ \\
$\mathrm{~S}$ & $689,0^{* *}$ & $211,8^{* *}$ & $658,4^{* *}$ & $225,6^{* *}$ & $11,9^{* *}$ & $26,4^{* *}$ & $637,4^{* *}$ & $230,9^{* *}$ \\
$\mathrm{AS}$ & $47,9^{* *}$ & $11,2^{* *}$ & $48,3^{* *}$ & $66,0^{* *}$ & $13,6^{* *}$ & $47,9^{* *}$ & $39,1^{* *}$ & $47,8^{* *}$ \\
$\mathrm{RS}$ & $116,8^{* *}$ & $11,6^{* *}$ & $246,7^{* *}$ & $67,3^{* *}$ & $20,1^{* *}$ & $58,6^{* *}$ & $199,6^{* *}$ & $54,1^{* *}$ \\
$\mathrm{ARS}$ & $26,6^{* *}$ & $43,4^{* *}$ & $42,4^{* *}$ & $88,4^{* *}$ & $26,2^{* *}$ & $44,8^{* *}$ & $60,6^{* *}$ & $70,9^{* *}$ \\
\hline
\end{tabular}

${ }^{1} \mathrm{CV}=$ causa de variação; $\mathrm{A}=$ ambientes; $\mathrm{R}=$ recipientes; $\mathrm{AR}=$ interação entre ambientes e recipientes; $\mathrm{S}=$ substratos; $\mathrm{AS}=$ interação entre ambientes e substratos; RS = interação entre recipientes e substratos; ARS = interação entre ambientes, recipientes e substratos; ${ }^{\text {NS }}=$ não significativo; $*=$ significativo $5 \% ; *$; $=$ significativo $1 \%$

Tabela 5 - Interações entre ambientes (A) e recipientes (R). Aquidauana - MS, 2009

\begin{tabular}{|c|c|c|c|c|}
\hline & \multicolumn{2}{|c|}{------------Altura de planta $(\mathrm{cm})-----------$} & \multicolumn{2}{|c|}{------------Diâmetro do colo $(\mathrm{mm})$------------ } \\
\hline & Viveiro & Estufa & Viveiro & Estufa \\
\hline 72 células & 4,0 $\mathrm{Aa}^{*}$ & $3,7 \mathrm{Ab}$ & - & - \\
\hline \multirow[t]{2}{*}{128 células } & $3,2 \mathrm{Ba}$ & $3,1 \mathrm{Ba}$ & - & - \\
\hline & \multicolumn{2}{|c|}{------Massa seca da parte aérea (g)------- } & \multicolumn{2}{|c|}{-----Massa seca do sistema radicular (g)---- } \\
\hline 72 células & $0,047 \mathrm{Aa}$ & $0,037 \mathrm{Ab}$ & $0,018 \mathrm{Aa}$ & $0,0122 \mathrm{Ab}$ \\
\hline \multirow[t]{2}{*}{128 células } & $0,019 \mathrm{Bb}$ & $0,023 \mathrm{Ba}$ & $0,008 \mathrm{Bb}$ & $0,0098 \mathrm{Ba}$ \\
\hline & \multicolumn{2}{|c|}{--Relação altura e diâmetro $\left(\mathrm{cm} \mathrm{mm}^{-1}\right)--$} & \multicolumn{2}{|c|}{------Relação massa seca aérea e raiz------ } \\
\hline 72 células & $2,30 \mathrm{Aa}$ & $2,06 \mathrm{Ab}$ & $2,90 \mathrm{Ab}$ & $3,65 \mathrm{Aa}$ \\
\hline \multirow[t]{2}{*}{128 células } & $2,20 \mathrm{Ba}$ & $2,09 \mathrm{Ab}$ & $2,28 \mathrm{Bb}$ & $2,53 \mathrm{Ba}$ \\
\hline & \multicolumn{2}{|c|}{-----------Massa seca total (g)------------- } & \multicolumn{2}{|c|}{-----Índice de qualidade de Dickson----- } \\
\hline 72 células & $0,065 \mathrm{Aa}$ & $0,049 \mathrm{Ab}$ & $0,013 \mathrm{Aa}$ & $0,010 \mathrm{Ab}$ \\
\hline 128 células & $0,027 \mathrm{Bb}$ & $0,032 \mathrm{Ba}$ & $0,006 \mathrm{Bb}$ & $0,007 \mathrm{Ba}$ \\
\hline
\end{tabular}

*Letras iguais maiúsculas nas colunas e minúsculas nas linhas não diferem entre si pelo Teste de Tukey a 0,05 
pois neste recipiente as plântulas apresentaram melhor desenvolvimento no viveiro telado. Mesmo estando na mesma condição de ambiente de cultivo que as bandejas de 128 células, o maior volume celular da bandeja de 72 células permitiu menos carreamento de nutrientes e melhor desenvolvimento às mudas.

A umidade relativa no viveiro com tela de monofilamento foi maior que a da estufa agrícola nos horários de coleta (TAB. 3). Essa maior umidade possibilitou menor quantidade de água de irrigação, pois a estrutura da tela permitiu a entrada de água pluvial. Além desse aspecto, a maior umidade relativa nesse ambiente diminui a evapotranspiração (COSTA et al., 2009), permitindo às mudas melhor acondicionamento ambiental.

As condições ambientais do viveiro, com maior umidade relativa, propiciaram condições mais adequadas para o desenvolvimento da muda de berinjela, sendo mais vigorosas e propícias para enfrentarem as condições adversas a campo. Aliada a estas condições ambientais favoráveis e ao maior volume celular que permitiu maior disponibilidade de nutrientes, água e espaço poroso, assim as raízes se desenvolveram melhor, as plantas acumularam maior biomassa seca e inferiram melhor qualidade às mudas formadas na bandeja de 72 células.

Segundo Gomes (2001) a fórmula que determina o IQD é balanceada, pois inclui parâmetros morfológicos de altura, diâmetro e biomassas (IQD = $\mathrm{MST} /(\mathrm{RAD}+\mathrm{RMS})$. Quanto maior o valor do índice maior é o padrão de qualidade das mudas. As maiores mudas, com maiores biomassas e melhores índices de desenvolvimento (IQD) foram obtidas nas proporções medianas de vermiculita e ramas de mandioca (S3 e $\mathrm{S} 4$ ), tanto para os ambientes de cultivo como para as bandejas de poliestireno, com pequena superioridade pelo S4 (TAB. 6 e 7).

Provavelmente as proporções medianas (entre 40 e $60 \%$ ) dos materiais que constituíram os substratos S3 e S4, em comparação com os demais, apresentaram superioridade por proporcionarem maior fixação e crescimento das raízes. Nestas proporções, a granulometria (TAB. 2) possibilitou melhor disponibilidade de umidade e aeração, refletindo em maior crescimento das raízes, promovendo plântulas com maiores biomassas, e conseqüentemente mais vigorosas. Oliveira et al. (2008) obtiveram mudas de pimentão e alface com maiores matérias secas, quando utilizaram vermiculita pura ou na proporção de $50 \%$ em mistura com substrato comercial. Negreiros et al. (2004) e Costa et al.(2009) destacaram as propriedades da vermiculita como excelente condicionador do sistema radicular de mudas, devido sua grande capacidade de retenção de água em função da alta porosidade, promovendo melhor desenvolvimento da muda.

A rama de mandioca triturada, possuindo $50 \%$ de partículas entre 2,0 e 4,0 $\mathrm{mm}$ e aproximadamente $48 \%$ de partículas menores que 2,0 mm (TAB. 2), foi uma alternativa na produção de mudas de berinjela, quando misturada a $50 \%$ de vermiculita, diminuindo custo de produção com o substrato. Por ser um resíduo novo, em estudo para composição de substratos, abrem-se outras possibilidades para testar a rama de mandioca com tempo maior de secagem (acima de 7 dias), possível compostagem ("cura") visando diminuir a relação carbono e nitrogênio, carbonizada como se faz com a palha de arroz e em outras granulometrias. Estas modificações poderão permitir o uso de maior porcentagem do material de fácil aquisição e baixo custo.

O diâmetro do colo estima a sobrevivência das mudas após o plantio (GOMES, 2001). Nesse raciocínio, as plântulas mais propícias para terem sucesso a campo foram produzidas nos substratos S3 e S4, em ambos ambientes e na bandeja de 72 células. Segundo o mesmo autor a relação altura/diâmetro exprime o equilíbrio de crescimento, sendo considerado um índice de qualidade que exprime dois parâmetros morfológicos simultaneamente. Para mudas florestais, quanto menor seu valor maior será a capacidade das mudas sobreviverem a campo. Para as mudas de berinjela esse parâmetro isolado não exprimiu com rigorosidade a qualidade da muda, ficando entre $1,87 \mathrm{e}$ 2,31 (TAB. 6). No entanto o IQD, que envolve vários parâmetros de crescimento, foi um bom indicador do padrão de qualidade das mudas de berinjela.

Todos os substratos permitiram crescimento uniforme das plântulas nos recipientes e ambientes avaliados, apresentando alto coeficiente de determinação $\left(\mathrm{R}^{2}\right)$ e inferindo incremento linear na altura da muda em função do tempo (FIG. 1; 2; 3 e 4). Para a bandeja de 72 células no viveiro, e para a bandeja de 128 células na estufa, as maiores correlações (acima de 99\%) foram verificadas nos substratos S3 e S4 (FIG. 1 e 4). Esse crescimento mais uniforme nos substratos com proporções medianas dos dois componentes, observado desde a emergência até aos 56 DAS, revelam que as plântulas se adaptaram melhor nessas composições. Conforme verificado, também, através de outros parâmetros de avaliação.

Observa-se que os coeficientes angulares das equações estão entre zero e um, pois as datas de coletas correspondem aos dias após a semeadura $(27 ; 34 ; 41$ e $48 \mathrm{DAS})$ e as plantas atingiram altura máxima próximo de $6,0 \mathrm{~cm}$. 
Tabela 6 - Interações entre ambientes (A) e substratos (S), entre recipientes (R) e substratos (S) para a altura de planta, diâmetro do colo, relação altura e diâmetro e índice de qualidade de Dickson. Aquidauana - MS, 2009

\begin{tabular}{|c|c|c|c|c|}
\hline \multirow{2}{*}{ Tratamentos } & Viveiro & Estufa & 72 células & 128 células \\
\hline & \multicolumn{4}{|c|}{ - } \\
\hline $\mathrm{S} 1 * *$ & $3,2 \mathrm{Ca}^{*}$ & $2,7 \mathrm{Fb}$ & 3,1 Ea & $2,8 \mathrm{Db}$ \\
\hline S2 & $3,3 \mathrm{Ca}$ & $3,3 \mathrm{Ca}$ & $3,7 \mathrm{Ca}$ & $3,0 \mathrm{Cb}$ \\
\hline S3 & $4,6 \mathrm{Ba}$ & $4,0 \mathrm{Bb}$ & $4,7 \mathrm{Ba}$ & $3,9 \mathrm{Ab}$ \\
\hline S4 & 4,9 Aa & $4,2 \mathrm{Ab}$ & $5,5 \mathrm{Aa}$ & $3,6 \mathrm{Bb}$ \\
\hline S5 & $3,0 \mathrm{Da}$ & 3,1 Da & 3,3 Da & $2,8 \mathrm{Db}$ \\
\hline \multirow[t]{2}{*}{ S6 } & $2,7 \mathrm{~Eb}$ & 2,9 Ea & $3,0 \mathrm{Ea}$ & $2,7 \mathrm{Db}$ \\
\hline & \multicolumn{4}{|c|}{ - } \\
\hline S1 & 1,43 Ba & $1,36 \mathrm{Cb}$ & $1,51 \mathrm{Ca}$ & $1,28 \mathrm{Bb}$ \\
\hline S2 & $1,53 \mathrm{Bb}$ & 1,64 Ba & $1,81 \mathrm{Ba}$ & $1,36 \mathrm{Bb}$ \\
\hline S3 & 1,96 Аa & 1,93 Aa & 2,16 Aa & $1,73 \mathrm{Ab}$ \\
\hline S4 & 2,00 Aa & 2,02 Aa & 2,19 Aa & $1,83 \mathrm{Ab}$ \\
\hline S5 & $1,31 \mathrm{Cb}$ & $1,58 \mathrm{Ba}$ & $1,55 \mathrm{Ca}$ & $1,34 \mathrm{Bb}$ \\
\hline \multirow[t]{2}{*}{ S6 } & $1,46 \mathrm{Ba}$ & $1,41 \mathrm{Ca}$ & $1,51 \mathrm{Ca}$ & $1,36 \mathrm{Bb}$ \\
\hline & \multicolumn{4}{|c|}{ 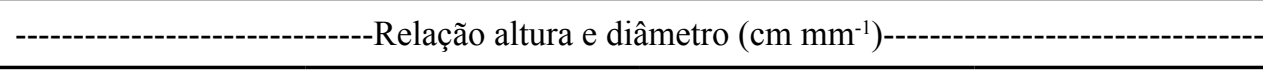 } \\
\hline S1 & $2,31 \mathrm{ABa}$ & $2,01 \mathrm{Ab}$ & $2,10 \mathrm{BCa}$ & $2,22 \mathrm{ABa}$ \\
\hline $\mathrm{S} 2$ & $2,20 \mathrm{Ba}$ & $2,07 \mathrm{Ab}$ & $2,05 \mathrm{BCb}$ & $2,22 \mathrm{ABa}$ \\
\hline S3 & $2,35 \mathrm{ABa}$ & $2,18 \mathrm{Ab}$ & 2,20 Bb & 2,33 Aa \\
\hline S4 & $2,45 \mathrm{Aa}$ & 2,08 Ab & 2,54 Aa & $1,99 \mathrm{Cb}$ \\
\hline S5 & 2,34 $\mathrm{ABa}$ & $2,01 \mathrm{Ab}$ & 2,21 Ba & $2,14 \mathrm{BCa}$ \\
\hline \multirow[t]{2}{*}{ S6 } & $1,87 \mathrm{Cb}$ & 2,10 Aa & $1,99 \mathrm{Ca}$ & $1,98 \mathrm{Ca}$ \\
\hline & \multicolumn{4}{|c|}{ - } \\
\hline S1 & 0,013 Aa & $0,004 \mathrm{Cb}$ & $0,012 \mathrm{Ca}$ & $0,005 \mathrm{Cb}$ \\
\hline $\mathrm{S} 2$ & $0,007 \mathrm{Ba}$ & $0,005 \mathrm{Cb}$ & 0,006 DEa & $0,005 \mathrm{Ca}$ \\
\hline S3 & $0,013 \mathrm{Ab}$ & $0,015 \mathrm{Aa}$ & $0,017 \mathrm{Ba}$ & $0,011 \mathrm{Ab}$ \\
\hline S4 & 0,014 Aa & 0,014 Aa & 0,019 Аa & $0,009 \mathrm{Bb}$ \\
\hline S5 & $0,006 \mathrm{BCb}$ & $0,007 \mathrm{Ba}$ & 0,007 Da & $0,006 \mathrm{Cb}$ \\
\hline S6 & $0,005 \mathrm{Ca}$ & $0,005 \mathrm{Ca}$ & $0,005 \mathrm{Ea}$ & $0,004 \mathrm{Ca}$ \\
\hline
\end{tabular}

* Letras iguais maiúsculas nas colunas e minúsculas nas linhas não diferem entre si pelo Teste de Tukey a 0,05 de probabilidade. ** $\mathrm{S} 1=$ " $0 \%$ vermiculita e $100 \%$ ramas"; S2 = "20\% vermiculita e $80 \%$ ramas"; S3 = " $40 \%$ vermiculita e $60 \%$ ramas"; S4 = " $60 \%$ vermiculita e $40 \%$ ramas"; S5 $=$ " $80 \%$ vermiculita e $20 \%$ ramas"; S6 = " $100 \%$ de vermiculita e $0 \%$ ramas" 
Tabela 7 - Interações entre ambientes (A) e substratos (S), entre recipientes (R) e substratos (S) para massa seca da parte aérea, massa seca do sistema radicular, relação massa seca da parte aérea/radicular e massa seca total. Aquidauana - MS, 2009

\begin{tabular}{|c|c|c|c|c|}
\hline \multirow{2}{*}{ Tratamentos } & Viveiro & Estufa & 72 células & 128 células \\
\hline & \multicolumn{4}{|c|}{ 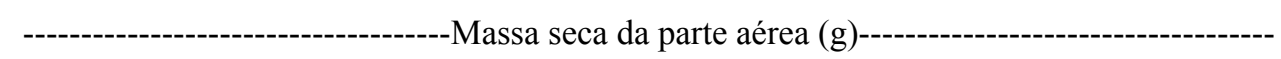 } \\
\hline S1 & $0,020 \mathrm{Da}$ & $0,016 \mathrm{Db}$ & $0,020 \mathrm{Ea}$ & $0,016 \mathrm{CDb}$ \\
\hline S2 & $0,025 \mathrm{Ca}$ & $0,022 \mathrm{Ca}$ & $0,032 \mathrm{Ca}$ & $0,016 \mathrm{Db}$ \\
\hline S3 & $0,055 \mathrm{Ba}$ & $0,046 \mathrm{Ab}$ & $0,067 \mathrm{Ba}$ & $0,034 \mathrm{Ab}$ \\
\hline S4 & $0,067 \mathrm{Aa}$ & $0,049 \mathrm{Ab}$ & $0,089 \mathrm{Aa}$ & $0,027 \mathrm{Bb}$ \\
\hline S5 & $0,017 \mathrm{DEb}$ & $0,028 \mathrm{Ba}$ & $0,025 \mathrm{Da}$ & $0,020 \mathrm{Cb}$ \\
\hline \multirow[t]{2}{*}{ S6 } & $0,014 \mathrm{Ea}$ & $0,017 \mathrm{Da}$ & $0,020 \mathrm{Ea}$ & $0,011 \mathrm{~Eb}$ \\
\hline & \multicolumn{4}{|c|}{-Massa seca do sistema radicular (g)-- } \\
\hline S1 & $0,020 \mathrm{Aa}$ & $0,006 \mathrm{Db}$ & $0,019 \mathrm{Ca}$ & $0,006 \mathrm{CDb}$ \\
\hline S2 & $0,009 \mathrm{Ca}$ & $0,006 \mathrm{Db}$ & $0,008 \mathrm{DEa}$ & 0,008 CDa \\
\hline S3 & $0,017 \mathrm{Bb}$ & $0,021 \mathrm{Aa}$ & $0,023 \mathrm{Ba}$ & $0,016 \mathrm{Ab}$ \\
\hline S4 & $0,019 \mathrm{ABa}$ & 0,019 Ba & $0,026 \mathrm{Aa}$ & $0,012 \mathrm{Bb}$ \\
\hline S5 & 0,008 CDa & $0,009 \mathrm{Ca}$ & 0,009 Da & $0,008 \mathrm{Ca}$ \\
\hline S6 & $0,006 \mathrm{Da}$ & $0,006 \mathrm{Da}$ & 0,006 Ea & $0,005 \mathrm{Da}$ \\
\hline S1 & $1,64 \mathrm{Cb}$ & $2,86 \mathrm{Ca}$ & $1,87 \mathrm{Db}$ & 2,62 $\mathrm{ABa}$ \\
\hline S2 & $2,58 \mathrm{Bb}$ & 4,56 Аa & 5,05 Aa & $2,08 \mathrm{Cb}$ \\
\hline S3 & $3,16 \mathrm{Aa}$ & $2,26 \mathrm{Db}$ & $3,06 \mathrm{BCa}$ & $2,36 \mathrm{BCb}$ \\
\hline S4 & 3,34 Aa & $2,54 \mathrm{CDb}$ & $3,46 \mathrm{Ba}$ & $2,42 \mathrm{BCb}$ \\
\hline S5 & 2,34 Bb & $3,46 \mathrm{Ba}$ & $2,85 \mathrm{Ca}$ & 2,96 Aa \\
\hline S6 & $2,48 \mathrm{Bb}$ & $2,88 \mathrm{Ca}$ & $3,36 \mathrm{Ba}$ & $2,00 \mathrm{Cb}$ \\
\hline S1 & $0,040 \mathrm{Ca}$ & $0,021 \mathrm{Db}$ & $0,038 \mathrm{CDa}$ & $0,022 \mathrm{Cb}$ \\
\hline S2 & $0,035 \mathrm{Ca}$ & $0,028 \mathrm{Cb}$ & $0,040 \mathrm{Ca}$ & $0,023 \mathrm{Cb}$ \\
\hline S3 & $0,072 \mathrm{Ba}$ & $0,067 \mathrm{Aa}$ & 0,090 Ba & $0,050 \mathrm{Ab}$ \\
\hline S4 & $0,086 \mathrm{Aa}$ & $0,068 \mathrm{Ab}$ & $0,115 \mathrm{Aa}$ & 0,039 Bb \\
\hline S5 & $0,025 \mathrm{Db}$ & 0,036 $\mathrm{Ba}$ & 0,033 Da & $0,028 \mathrm{Cb}$ \\
\hline S6 & $0,020 \mathrm{Da}$ & $0,023 \mathrm{CDa}$ & 0,026 Ea & $0,016 \mathrm{Db}$ \\
\hline
\end{tabular}

* Letras iguais maiúsculas nas colunas e minúsculas nas linhas não diferem entre si pelo Teste de Tukey a 0,05 de probabilidade. ** $\mathrm{S} 1=$ " $0 \%$ vermiculita e $100 \%$ ramas"; S2 = "20\% vermiculita e $80 \%$ ramas"; S3 = " $40 \%$ vermiculita e $60 \%$ ramas"; S4 = " $60 \%$ vermiculita e $40 \%$ ramas"; $\mathrm{S} 5=$ " $80 \%$ vermiculita e $20 \%$ ramas"; S6 = " $100 \%$ de vermiculita e $0 \%$ ramas" 


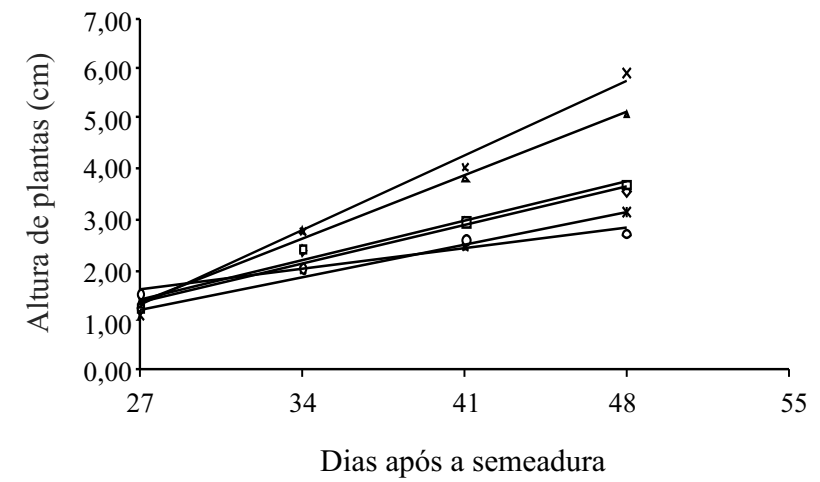

\begin{tabular}{|c|c|c|}
\hline A1R1S1 & yA1R1S1 $=-1,6192+0,1102 x * *$ & $\mathrm{R}^{2}=0,9$ \\
\hline$\Rightarrow \mathrm{Al}$ & yA1R1S2 $=-1,6621+0,1129 x^{* *}$ & $\mathrm{R}^{2}=0,9744$ \\
\hline$\triangle \mathrm{A} 1$ & yA1R1S3 $=-3,4375+0,1781 x^{*}$ & $\mathrm{R}^{2}=0,9958$ \\
\hline ×A1R1 & yA1R1S4 $=-4,458+0,2126 x^{*}$ & $\mathrm{R}^{2}=0,9911$ \\
\hline A & yA1R1S5 = - 1,3594 + 0,0938x* & $\mathrm{R}^{2}=0,9846$ \\
\hline - A1R1S6 & yA1R1S6 $=-0,017+0,0593 x * *$ & $\mathrm{R}^{2}=0,95$ \\
\hline
\end{tabular}

Os parâmetros das equações de regressão avaliados pelo teste t de Student são: * = significativo ao nível de 0,01 de probabilidade $(\mathrm{p}<0,01) ; * *=$ significativo ao nível de $0,05(\mathrm{p}<0,05)$

Figura 1 - Curva de crescimento da muda ao longo do tempo nos substratos ( 1 1 a S6) da bandeja de 72 células (R1) dentro do viveiro agrícola (A1).

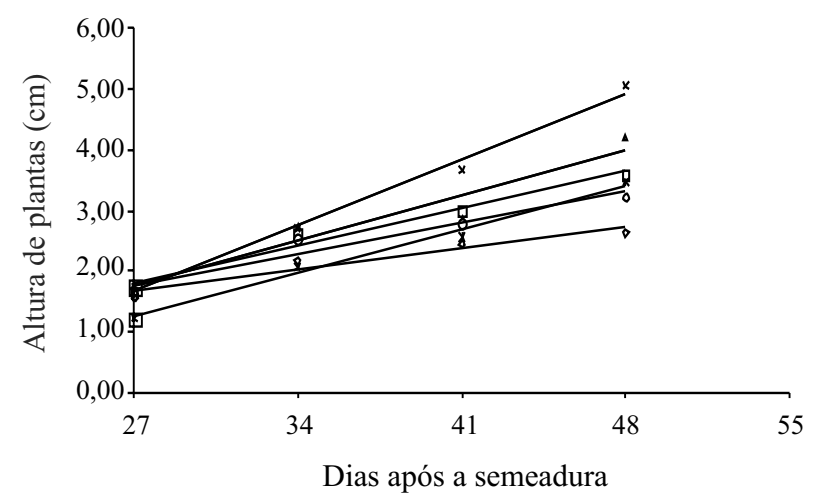

$\begin{array}{lll}\triangle A 2 R 1 S 1 & \text { yA2R1S1 }=0,3353+0,0496 x^{* *} & \mathrm{R}^{2}=0,9255 \\ \text { ×A2R1S2 } & \text { yA2R1S2 }=-0,5817+0,0877 x^{* *} & \mathrm{R}^{2}=0,9699 \\ \triangle \mathrm{A} 2 \mathrm{R} 1 \mathrm{~S} 3 & \mathrm{yA2R} 1 \mathrm{~S} 3=-1,1129+0,1064 \mathrm{x}^{* *} & \mathrm{R}^{2}=0,9191 \\ \text { ×A2R1S4 } & \text { yA2R1S4 }=-2,5616+0,1559 x^{*} & \mathrm{R}^{2}=0,9889 \\ \text { ×2R1S5 } & \text { yA2R1S5 }=-1,5205+0,1026 x^{*} & \mathrm{R}^{2}=0,9863 \\ \text { ×A2R1S6 } & \text { yA2R1S6 }=-0,1983+0,0729 x^{* *} & \mathrm{R}^{2}=0,9267\end{array}$

Os parâmetros das equações de regressão avaliados pelo teste t de Student são: * = significativo ao nível de 0,01 de probabilidade $(\mathrm{p}<0,01) ; * *=$ significativo ao nível de $0,05(\mathrm{p}<0,05)$

Figura 3 - Curva de crescimento da muda ao longo do tempo nos substratos ( $\mathrm{S} 1$ a S6) da bandeja de 72 células (R1) dentro da estufa agrícola (A2).

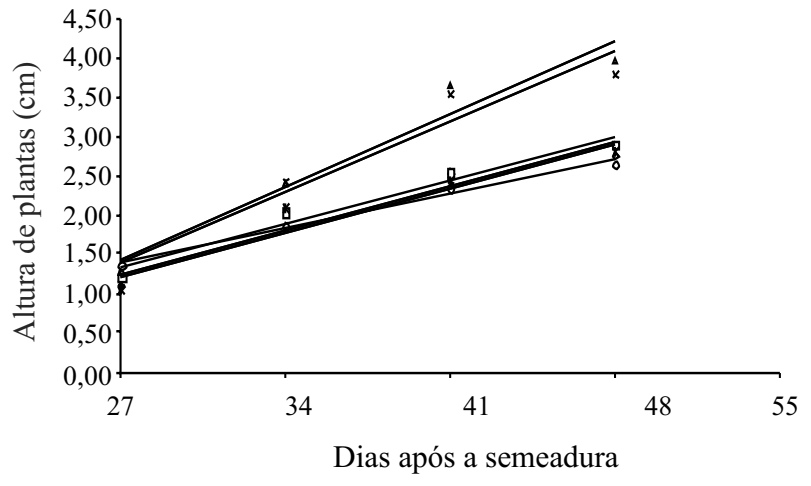

- A1R2S1

-A1R2S2

$\triangle \mathrm{A} 1 \mathrm{R} 2 \mathrm{~S} 3$

$\times \mathrm{A} 1 \mathrm{R} 2 \mathrm{~S} 4$

$\times$ A1R2S5

-A1R2S6

Os parâmetros das equações de regressão avaliados pelo teste t de Student são: * = significativo ao nível de 0,01 de probabilidade $(\mathrm{p}<0,01) ; * *=$ significativo ao nível de $0,05(\mathrm{p}<0,05)$

Figura 2 - Curva de crescimento da muda ao longo do tempo nos substratos ( $\mathrm{S} 1$ a S6) da bandeja de 128 células (R2) dentro do viveiro agrícola (A1).

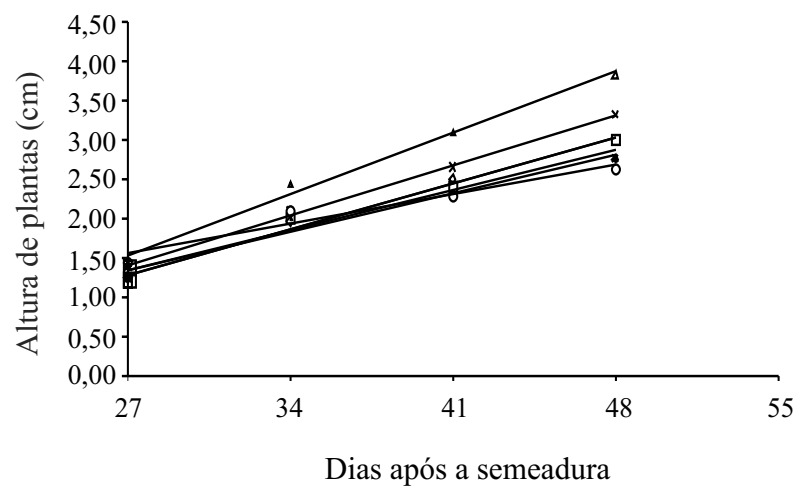

$$
\begin{array}{lll}
\triangle A 2 R 2 S 1 & \text { yA2R2S1 }=-0,5915+0,0722 x^{* *} & R^{2}=0,9563 \\
\text {-A2R2S2 } & \text { yA2R2S2 }=-0,9942+0,0839 x^{*} & R^{2}=0,9853 \\
\text { A2R2S3 } & \text { yA2R2S3 }=-1,5036+0,1121 x^{*} & R^{2}=0,992 \\
\text { ×A2R2S4 } & \text { yA2R2S4 }=-1,0558+0,0911 x^{*} & R^{2}=0,9983 \\
\text { ×A2R2S5 } & \text { yA2R2S5 }=-0,5518+0,0701 x^{* *} & R^{2}=0,9621 \\
\text {-A2R2S6 } & \text { yA2R2S6 }=0,1+0,0538 x^{* *} & R^{2}=0,9371
\end{array}
$$

Os parâmetros das equações de regressão avaliados pelo teste t de Student são: * = significativo ao nível de 0,01 de probabilidade $(\mathrm{p}<0,01) ; * *=$ significativo ao nível de 0,05 de probabilidade $(\mathrm{p}<0,05)$

Figura 4 - Curva de crescimento da muda ao longo do tempo nos substratos (S1 a S6) da bandeja de 128 células (R2) dentro da estufa agrícola (A2). 


\section{Conclusões}

1. A tela de monofilamento é o melhor ambiente de cultivo quando utiliza-se a bandeja de 72 células e, quando se utiliza a bandeja de 128 células a estufa agrícola propicia melhores condições;

2. O melhor recipiente para formação de mudas de berinjela é a bandeja de 72 células;

3. As composições medianas de vermiculita e ramas de mandioca, entre 40 e $60 \%$, formam o melhor substrato para as mudas de berinjela;

4. O índice de qualidade de Dickson é um bom indicador do padrão de qualidade e do vigor de mudas de berinjela.

\section{Referências}

BEZERRA, F. C. Produção de mudas de hortaliças em ambiente protegido. Fortaleza: Embrapa agroindústria tropical, 2003. 19 p. (Documento, 72).

CAMPANHARO, M. et al. Características físicas de diferentes substratos para produção de mudas de tomateiro. Caatinga, v. 19, n. 02, p. 140-145, 2006.

COSTA E. et al. Efeitos da ambiência, recipientes e substratos no desenvolvimento de mudas de maracujazeiro-amarelo em Aquidauana - MS. Revista Brasileira de Fruticultura, v. 31, n. 01, p. 236-244, 2009

DICKSON, A; LEAF, A. L; HOSNER, J. F. Quality appraisal of white spruce and white pine seedling stock in nurseries. Forestry Chronicle, v. 36, p. 10-13, 1960.

ECHER, M. M. et al. Avaliação de mudas de beterraba em função do substrato e do tipo de bandeja. Semina: Ciências Agrárias, v. 28, n. 01, p. $45-50,2007$.

ESTAT. Sistema para análises estatísticas versão 2.0-. Jaboticabal: Departamento de Ciências Exatas, Faculdade de Ciências Agrárias e Veterinárias, Universidade Estadual Paulista, 1994.

FILGUEIRA, F. A. R. Solanáceas: agrotecnologia moderna na produção de tomate, batata, pimentão, pimenta, berinjela, e jiló. Lavras: UFLA, 2003. 333 p.

GOMES, J. M. Parâmetros morfológicos na avaliação da qualidade de mudas de Eucalyptus grandis, produzidas em diferentes tamanhos de tubete e de dosagens de N-P-K. 2001.
126 f. Tese (Doutorado em Ciência Florestal) - Universidade Federal de Viçosa, Viçosa.

GUIMARÃES, V.F.; ECHER, M. M.; MINAMI, K. Métodos de produção de mudas, distribuição de matéria seca e produtividade de plantas de beterraba. Horticultura Brasileira, v. 20, n. 03, p. 505-509, 2002.

MARQUES, P. A. A. et al. Qualidade de mudas de alface formadas em bandejas de isopor com diferentes números de células. Horticultura Brasileira, v. 21, n. 04, p. 649-651, 2003.

MODOLO, V. A.; TESSARIOLI NETO, J.; ORTIGOZZA, L. E. R. Desenvolvimento de mudas de quiabeiro [Abelmoschus esculentus (L.) Moench] em diferentes tipos de bandeja e substrato. Scientia Agrícola, v. 56, n. 02, p. 377-381, 1999.

NEGREIROS, J. R. S. et al. Diferentes substratos na formação de mudas de maracujazeiro-amarelo. Revista Ceres, v. 51, n. 294, p. 243-249, 2004.

OLIVEIRA, D. A. et al. Produção de mudas de pimentão e alface em diferentes combinações de substrato. Revista Verde, v. 03, n. 01, p. $133-137,2008$.

OLIVEIRA, A. B.; HERNANDEZ, F. F. F.; ASSIS JÚNIOR, R. N. Absorção de nutrientes em mudas de berinjela cultivadas em pó de coco verde. Revista Caatinga, v. 22, n. 02, p. 139-143, 2009 .

PIOVESAN, M. F.; CARDOSO, A. I. I. Produção e qualidade de abóbora em função da idade das mudas e tipo de bandeja. Bragantiav. 68, n. 03, p. 651-656, 2009.

RIBEIRO, A. C; GUIMARÃES, P. T. G.; ALVAREZ, V. H. (Ed.) Recomendações para o uso de corretivos e fertilizantes em Mina Gerais. 5a Aproximação. Viçosa: UFV, 1999. 359 p.

SCHMITZ, J. A. K; SOUZA, P. V. D.; KAMPF, A. N. Propriedades químicas e físicas de substratos de origem mineral e orgânica para o cultivo de mudas em recipientes. Ciência Rural, v. 32, n. 06, p. 937-944, 2002.

SEABRA JÚNIOR, S.; GADUM, J.; CARDOSO, A. I. I. Produção de pepino em função da idade das mudas produzidas em recipientes com diferentes volumes de substrato. Horticultura brasileira, v. 22, n. 03, p. 610-613, 2004.

SOUSA, J. A.; LEDO, F. J. S.; SILVA, M. R. Produção de mudas de hortaliças em recipientes. Rio Branco: EmbrapaCPAF/AC, 1997. 19 p. (. Circular Técnica, 19).

TRANI, P. E. et al. Produção de mudas de alface em bandejas e substratos comerciais. Horticultura Brasileira, v. 22, n. 02, p. 290-294, 2004 